\title{
VIVENDO À FLOR DA PELE: A TATUAGEM COMO MARCA IDENTITÁRIA
}

\section{LIVING UNDER THE SKIN: THE TATTOO AS AN IDENTITY MARK}

\section{Clara Maduell Gómez}

claramaduellgomez@gmail.com

Bacharela e Licenciada em Ciências Sociais (UFRGS),

Mestre em Antropologia Social (UFPel).

ORCID: https://orcid.org/0000-0002-2883-0570

\section{(9) (1)(2)}

Esta obra está licenciada sob uma licença Creative Commons Attribution-NonCommercial-ShareAlike 4.0 International License.

\section{RESUMO}

Em todas as épocas e lugares do mundo, o ser humano usa o corpo como forma de linguagem. Enfeita-o para ser belo, diferente, mágico. Tradicionalmente, a sociedade também exerceu poder sobre o corpo do indivíduo, inscrevendo suas marcas de acordo com a cultura a que ele pertencia, mas hoje as modificações corporais têm se tornado uma forma de expressão individual de arte do corpo e vêm ganhando, a cada dia, mais adeptos. O presente estudo tem o objetivo de compreender a atuação da tatuagem como marcadora identitária nas classes médias urbanas e contemporâneas brasileiras e as percepções dos tatuados sobre seus corpos, suas marcas, a dor, o preconceito e a profissionalização dos tatuadores. É um recorte de um esforço etnográfico em duas convenções de tatuagem, dois estúdios de tatuagem e na casa de uma tatuadora todos em Porto Alegre, Rio Grande do Sul; e de coletas de dados através de entrevistas presenciais, também na capital gaúcha, e via formulário on-line com respostas de participantes de outras cidades do Brasil.

Palavras-chave: tatuagem; modificações corporais; identidade.

\section{ABSTRACT}

In all times and places in the world, human being has used their bodies as a form of language. Decorate it to be beautiful, different, and magical. Traditionally, society has also exercised power over the body of individuals, inscribing its marks according to the culture to which it belongs, but today body modifications have become a form of individual expression of body art and are gaining, every day, more fans. This study aims to understand the role of tattooing as an identity mark in the Brazilian urban and contemporary middle class, and the perceptions of those tattooed about their bodies, their marks, pain, prejudice, and the 
professionalization of tattoo artists. This is an excerpt from an ethnographic effort in two tattoo conventions; two tattoo studios and the house of a tattoo artist - all in Porto Alegre, Rio Grande do Sul; interviews were conducted face-to-face, also in the state capital, and with an online form, with responses from participants from other cities in Brazil.

Keywords: tattoo; body modification; identity.

\section{INTRODUÇÃO}

Através do corpo marcado e pintado, os homens se relacionam simbolicamente no contexto social; é uma forma de comunicação não verbal. A pele é lugar onde se fabrica a identidade. Tanto é assim que as marcas adicionadas deliberadamente se convertem em símbolos de identidade que aparecem na própria carne. O sentido do eu lança suas raízes na pele, como lugar imediato de contato com o outro e com o mundo (LE BRETON, 2013).

Se a pele expressa o mais íntimo de um indivíduo, por que tem gente que quer modificar seu aspecto, textura ou cor? As mudanças no corpo acabam sendo usadas para explicitar a identidade, o estilo de vida e o grupo no qual está inserido o sujeito. É de grande relevância, principalmente no capitalismo, cuja percepção do corpo é dominada por várias imagens que propõem padrões de representação corporal, umas influenciadas pela moda e outras contestatárias, que vão em direção oposta aos valores preestabelecidos.

Para a antropologia analisar as modificações corporais é necessário ter sobre o corpo uma noção histórica e cultural, além da natural. Quase todos os povos, desde os tempos mais remotos, já possuíam formas de adornar o corpo por motivos religiosos, estéticos e por tradições e costumes da própria cultura. Cada vez mais, percebemos que o ser humano faz de seu corpo um instrumento da mudança de sua "aparência natural”, podendo ela ser definitiva ou temporária. Mary Douglas (1978) identifica uma tendência natural a expressar determinado tipo de situações por meio de um estilo corporal adequado a elas. Essa tendência pode-se qualificar como natural conforme é inconsciente e se obedece a ela em todas as culturas.

O corpo é o modo de expressão do social; interdições e classificações são consequentemente acionadas por ele. As sociedades judaico-cristãs elevam o corpo à ideia de "Templo", que deve estar puro, limpo e imaculado. Como resultado dessa interação, o corpo em si constitui um meio de expressão sujeito a muitas limitações, tudo que macula essa suposta "natureza divina" é condenado. Mary Douglas (1991), por exemplo, busca entender tabus alimentares dentro do Antigo Testamento. Para ela, eles têm relação com a oposição que as culturas operam no mundo entre puro e impuro com referência à categoria central de "contamina- 
ção". Neste sentido, o controle sobre os corpos exerceu um papel importante do ponto de vista civilizatório e moral em uma lógica etnocêntrica.

O controle das práticas corporais foi uma das primeiras ações executadas para civilizar as sociedades chamadas "primitivas". De alguma forma, quanto mais marcados eram os outros, mais civilizado era o ocidente. Na América do Sul, os espanhóis e os portugueses encontraram sociedades ameríndias que cobriam seus corpos com adornos permanentes ou temporários. Essas formas de ornar o corpo suscitaram censura de imediato. Conforme Le Breton (2013), a colonização europeia e, sobretudo os missioneiros, foram destruindo grande parte das culturas cutâneas aqui presentes; qualquer modificação do corpo se entendia como selvageria ou indecência. Porém, cabe salientar que os europeus também tinham suas formas de marcação e adorno do corpo. Por exemplo, segundo o etnólogo José de Vasconcelos (apud JEHA, 2019), no século XIX a tatuagem com cunho religioso era praticada em aldeias portuguesas, inclusive por mulheres.

$\mathrm{Na}$ atualidade, cresce a incorporação e aceitação de práticas de exploração e modificação corporal. Há um processo de valorização da individualização dos corpos ampliando suas possibilidades no campo social, comercial e moral. Explorar o corpo é uma das tantas opções que oferece nossa sociedade como caminho de revalorização e/ou reencontro do corporal. Neste artigo, abordarei apenas uma das infinitas formas de mudar o corpo: a tatuagem.

Tatuagens são desenhos intradérmicos permanentes que se realizam injetando pigmentos específicos embaixo da epiderme por meio de microagulhas encaixadas em máquinas utilizadas somente para esse procedimento. Existem diversos estilos de tatuagem em termos de motivos, desenhos, cores e tipo de tradição, porém esses são apenas alguns padrões e podem misturar-se entre si.

Da onomatopeia "Tatau" do Taiti se origina o nome tattoo, palavra utilizada pelos nativos para a arte de pintar o corpo de modo definitivo. "Tatau" repetia o som do cabo de madeira que batia no ancinho de dentes afiados, usado para picar a pele e introduzir a tinta. O primeiro ocidental a ouvir o termo foi o capitão James Cook, que aportou no Taiti em 1769 e levou-o para a Inglaterra (ARAÚJO, 2005).

A palavra tatuagem foi introduzida no Ocidente no século XVIII, porém práticas semelhantes já eram populares na Europa desde a idade média, estando relacionadas com as cruzadas e formas posteriores de peregrinação religiosa. Ao surgir o termo, a tatuagem foi ainda mais difundida com as explorações dos europeus em contato com as culturas do Pacífico. A técnica se difundiu graças à prática dos marinheiros ingleses de se tatuarem. Surgiram alguns amadores a bordo dos navios e em grandes portos. A partir de 1920, tornou-se mais popular e comercial nos Estados Unidos e, durante muito tempo, esteve associada a classes socioeconômicas mais baixas. 
Segundo Silvana Jeha (2019), a tatuagem não "chegou" no território hoje brasileiro, pois muitos povos aqui já se tatuavam. A partir de 1500, marítimos e colonos portugueses começaram a desembarcar, alguns tinham corpos tatuados. Décadas depois, trouxeram à força africanos para serem escravizados e esses também exibiam marcas. Durante a grande imigração, na passagem do século XIX para o XX, outros europeus e orientais compuseram o mosaico de corpos marcados. A partir de uma lógica ocidental, no Brasil, a tatuagem se vislumbrou melhor com o dinamarquês Knud Harald Lucky Gegersen, que chegou a Santos em 1959 e abriu uma "loja” de tattoo na região portuária. A prática passou a ser usada por surfistas da região e marinheiros que chegavam ao porto da cidade litorânea. Lucky é reconhecido no meio como o primeiro profissional a trabalhar em terras brasileiras; teve uma participação de grande importância e foi graças a ele que o Brasil entrou no mapa da tatuagem moderna e vem conquistando aliados cotidianamente.

Trata-se, então, de tradições diferentes, pois no continente americano as tatuagens europeias entraram em contato com as culturas indígenas e africanas, ganhando novos significados. Assim, como a população brasileira, o corpo tatuado no Brasil foi forjado entre indígenas, africanos escravizados, colonos, imigrantes e mestiços de variado matiz, criando um resultado híbrido (JEHA, 2019). E, atualmente, no país, contamos com centenas de estúdios de tatuagem em funcionamento (ABREU; SOARES, 2012).

Este artigo tem o propósito de descobrir como a tatuagem contemporânea auxilia na afirmação da identidade do sujeito e objetiva entender qual o significado do corpo para os que optam por intervir nele por meio de tatuagens atualmente. Cabe ressaltar que todos os entrevistados, tanto presencial quanto virtualmente, despropositadamente, pertencem às classes médias urbanas do país. Assim, este artigo é uma análise de corpos em um contexto bastante situado (a maioria branca de classes médias urbanas) e não supõe a prática como representativa do lugar da tatuagem na sociedade brasileira como um todo. Dessa forma, não pretende ser um esforço comparativo de diferenças de classe, raça e etnias na relação com a tatuagem e não atenta para outros cenários como a tatuagem indígena, carcerária, entre outras.

$\mathrm{Na}$ conjuntura citada, a tatuagem seria apenas vaidade, uma tendência estética de culto ao corpo? Ou vontade de criar uma autoidentidade, um desejo de ir em direção oposta a padrões preestabelecidos, estéticos, culturais ou de conduta em vista da moda em grupos urbanos?

Este é um recorte do meu Trabalho de Conclusão de Curso de Bacharelado em Ciências Sociais, intitulado A pele marcada: um estudo antropológico sobre o corpo como superfície simbólica na sociedade urbana atual, que trata das modificações corporais de forma mais ampla. Para dar conta desse tema, o método de pesquisa que utilizei foi o qualitativo que, segundo Velho (1978), foi com o qual a antropologia se identificou. 
Assim, a observação participante, a entrevista aberta e o contato direto com o universo estudado tornaram-se marcas registradas da disciplina. Ao longo do curso de bacharelado em Ciências Sociais, fiz observações em dois estúdios, além de análise de procedimentos na casa de Camila, tatuadora que atende seus clientes em sua residência. Participei de duas convenções de tatuagem e piercing que contaram com a presença dos melhores tatuadores do sul do Brasil. Além dessas análises, fiz entrevistas em profundidade com os profissionais dos estúdios (nos eventos ninguém foi entrevistado) e com alguns conhecidos, homens e mulheres tatuados. Também coletei dados via formulário on-line com adeptos da tatuagem de vários estados do país; além de conversas virtuais em grupos de tatuados brasileiros na internet e relatos informais de muitas pessoas dentro dos estúdios na capital gaúcha. Esses diálogos possibilitaram a reunião de elementos sobre os diversos aspectos da vida social e do comportamento desses adeptos.

É interessante estudar mudanças que apareceram primeiro como distintivo de pequenos grupos, depois como expressão dos movimentos jovens, até ganhar a adesão de grande parte da população, aumentando, a cada dia, a incidência dessa prática. É notório o crescente o número de pessoas que têm tatuagens. Torna-se importante tentar entender essa linguagem e saber o porquê dos homens e mulheres sempre estarem em busca da mudança, o que ocorre há anos.

\section{A SOCIEDADE DO ESPETÁCULO}

Em novembro de 2013, compareci a $3^{a}$ Expo Tattoo RS, que ocorreu no centro de eventos Casa do Gaúcho no parque Harmonia, em Porto Alegre. Os organizadores convidavam os visitantes com a frase "Vem para quebrar tabus e preconceitos!”. O evento contou com a presença de Gaby e Victor Peralta, casal que figura no Guiness book como o mais modificado do mundo.

No início de 2014, ocorreu um encontro parecido. Combinei com alguns amigos interessados no assunto de ir ao Tattoo Show RS, realizado nos dias 12 e 13 de abril, também na Casa do Gaúcho, em Porto Alegre. A descrição dos coordenadores do evento no facebook era: "Serão dois dias de cultura e muita arte. Concurso de tatuagem e piercing e a presença do casal mais modificado do mundo".

Ambas tratavam-se de convenções de tatuagem e piercing com os melhores profissionais do sul do Brasil, onde há concursos e premiações para os melhores trabalhos eleitos pelo júri. Contaram com vários expositores de venda de tinta, máquinas para tatuagem, revistas e livros com modelos de desenho, além de acessórios, piercings e, obviamente, stands de estúdios de tatuagem. Os artistas escolheram modelos, normalmente voluntários que não precisavam pagar o trabalho, e tatuaram figuras enormes em um único dia (é necessário que a tatuagem seja feita no dia e no local para que possa concorrer). Duas conhecidas minhas serviram 
de modelo, uma para o tatuador Clayton Dias (Nego) e outra para Jorge Vilella, ambos, na época, do estúdio Verani Tattoo. Concorreram em categorias diferentes, nenhuma delas ganhou e as duas ficaram cerca de $8 \mathrm{~h}$ seguidas "na agulha".

A realização dos dois eventos foi feita pelo estúdio Neto Tattoo e eles não foram amplamente difundidos na mídia. A maioria do público é convidado pela própria rede social facebook. Os encontros são grandes oportunidades para que os profissionais, tanto body piercers como tatuadores, possam divulgar seus trabalhos, seus estúdios e suas técnicas. E, segundo os organizadores, estão "contribuindo com sua forte influência artística e cultural para a difusão da tatuagem como forma de expressão da arte e como empreendimento comercial".

Em todos os stands, ouvia-se o barulho da máquina de tatuagem e mais de um tatuador por espaço fazia sua arte. Muita gente circulava pelo interior da Casa do Gaúcho, a grande maioria das pessoas tinha tatuagens e piercings e trajava roupas pretas, normalmente camisetas de banda de rock. Também não eram raros os que tinham dreads e alargadores nos lóbulos. Um rapaz chamava a atenção com um pocket piercing ${ }^{1}$ na área do peito e da barriga (DIÁRIO DE CAMPO, 12 abr. 2014).

Nas duas convenções que frequentei, percebi que as pessoas não se olhavam nos olhos, mas focavam nas pinturas que as outras traziam. Vi gente que, quando não conseguia observar o suficiente "na passada", parava as pessoas, dizendo: "Moço/a, deixa eu ver tua tattoo?!". Também observei gente entrando nos espaços só para conhecer os trabalhos, querendo saber quais concorreriam. Ouvi comentários como "Aquela das flores na perna da menina é a mais bonita pra mim!". É um concurso extraoficial onde os tatuados se exibem e os outros comparam e julgam qual o melhor na sua opinião. O corpo é o eixo da interação social. O julgamento oficial ocorria no final do dia (concorrem também duas categorias de piercings), próximo das $19 \mathrm{~h}$. Anunciavam a categoria no palco, pediam para os modelos se posicionarem ao lado direito e os melhores trabalhos de cada série eram premiados.

Outros campos de observação foram dois estúdios que se pareciam bastante. Logo na entrada, a sala de espera tinha algumas cadeiras, um balcão e estantes expositoras onde ficam as joias de piercing, uma mesa com computador e uma prateleira que acomoda os catálogos de desenhos e revistas de tatuagens.

O primeiro, que tem maior área, conta com mais duas salas: uma para tatuagem e outra separada onde são realizados procedimentos de piercings, escarificações e bifurcações de língua. O segundo estúdio compartilha o espaço com um salão de beleza e uma divisória limita os dois estabelecimentos.

Ambos os estúdios são mobiliados com duas macas-cadeiras, parecidas com as de dentista, um balcão com tintas e agulhas, máquinas de tatuagem e a autoclave, que é usada para a esterilização dos equipa- 
mentos e das joias. Os locais são decorados com quadros e modelos de tatuagens.

Segundo Camilo Braz (2006), a profissionalização da tatuagem no Brasil ocorreu na década de 1980, quando surgiram os primeiros estúdios. Até o início dos anos 1970, as tatuagens seriam identificadas com situações de marginalidade. A partir da década de 1990, o procedimento tornou-se higienizado. Houve uma busca de materiais que não provocassem alergia e, também, de medicamentos para cicatrização, como pomadas. Apesar de não haver regulamentação da profissão, os estúdios começaram a atuar com alvarás e seus profissionais a se preocupar com a saúde.

Os tatuadores são autônomos, trabalham como prestadores de serviço e recebem por produção. Um grande percentual fica para o estabelecimento. Quando contatei Camila - tatuadora e uma das minhas interlocutoras - para saber se seria possível visitar o estúdio em que ela trabalhava, retornou-me informando que não atuava mais ali, uma vez que era mais vantajoso trabalhar na própria casa. No estúdio, ela tinha que repassar para o proprietário $50 \%$ do valor de cada tatuagem feita. Outra questão que deixa clara a fragilidade institucional dos técnicos do ramo é a falta de sindicatos.

Após alguns dias de campo, Bárbara, tatuadora, body piercer e gerente de um dos estúdios, me disse que iria à casa da Camila colocar um piercing em uma cliente e que, no mesmo dia, Camila tinha uma tatuagem agendada. Combinei, então, de encontrar Camila no centro da cidade para irmos juntas à casa dela. Antes, passamos na loja do Verani Tattoo para ela comprar agulhas descartáveis, pois não dispõe de autoclave. Chegamos à residência de Camila, na Cidade Baixa, e Bárbara chegou logo após:

Camila pôs uma trava na porta do quarto para que o cachorro não tivesse acesso. Colocou luvas e máscara descartáveis, pediu para que Jéssica deitasse na maca e começou o trabalho. Depois, chegou Elisa (22 anos), amiga de Camila, que faria perfuração com Bárbara. A moça queria furar os mamilos e escolheu uma entre as joias que Bárbara havia levado. A profissional fez a esterilização com álcool. As duas clientes compartilharam a maca. Enquanto Camila tatuava Jéssica, Bárbara media a distância dos piercings nos mamilos de Elisa. E Camila pediu: "quando tu fores furar me avisa que eu paro aqui pra não dar problema". (DIÁRIO DE CAMPO, 05 jul. 2012).

Achei interessante a ideia de acompanhar o trabalho de uma tatuadora iniciante que preferia trabalhar em casa por questões financeiras. Pude entender como é difícil o acesso de principiantes nesse setor e o quanto eles precisam trabalhar precariamente até se estabelecer.

Durante a observação nos estúdios, descobri que a maioria dos tatuadores e body piercer, mesmo os profissionais e todos os funcionários dos estúdios, não possui carteira assinada. Um dos motivos é a profissão 
ainda não estar regulamentada. Portanto, em caso de eventuais problemas, eles não são cobertos pela Previdência e não possuem seguros previdenciários.

Uma constante na fala dos entrevistados é a noção de que a body modification $^{2}$ é uma área que exige o aprimoramento contínuo e crescente agregação de conhecimento de novas técnicas de trabalho. Pude notar que os profissionais exibem muitas modificações porque testam as técnicas em seus próprios corpos. Itamar, um dos entrevistados, me contou que precisava experimentar todas as modificações para explicar "como é" para os clientes que têm dúvidas. Camila relatou que tem "um monte de tatuagem feia nas coxas, porque era ali que treinava”.

O perfil dos tatuadores entrevistados é o mesmo: profissionais qualificados, todos fizeram cursos de tatuagem (alguns também de piercing), preocupados com a higiene, a biossegurança, com procedimentos seguros que não os põem em risco nem os clientes. Os estúdios deixaram de ser locais "clandestinos" e ficaram parecidos com clínicas médicas, dando muita atenção para a salubridade.

Em um dos estúdios visitados, a importância da assepsia apareceu muito na fala da gerente, Bárbara, e a limpeza do local de trabalho foi bastante ressaltada. Contou-me que a autoclave era o melhor método para a esterilização de materiais e ferramentas de trabalho e, ainda, que esse aparelho era submetido a testes periódicos para a certificação do funcionamento.

Camila também demonstrou uma grande preocupação com a assepsia, em seu caso com a utilização de materiais descartáveis, pois não possuía a autoclave para minimizar os possíveis riscos de infecção e transmissão de doenças sexualmente transmissíveis.

É uma profissão que é bastante saturada, porém são poucos que agem com responsabilidade com seus clientes e procuram evoluir sempre. Mas está em ascensão e, com o tempo, a tendência é o preconceito diminuir (CAMILA).

Percebi, na casa de Camila, que ela trancou o ambiente para que o cachorro não tivesse acesso e, além de usar agulhas e luvas descartáveis, tomou o cuidado de pôr plástico filme novo na máquina usada para tatuar. Era uma situação provisória, sua meta era juntar dinheiro tatuando em casa para depois abrir um estúdio próprio, evitando repassar percentual de seus trabalhos para o dono.

Impressionou-me a importância que Bárbara dava em ter conhecimento de anatomia, biossegurança e primeiros socorros. Ela tem diploma de técnica de enfermagem e necessidade de um aperfeiçoamento continuado:

Conforme os anos foram se passando, fiz um técnico de enfermagem para ter algum diferencial e também aprender um pouco mais, até para os piercings extremos. Na época eu estava colocando vários surfaces ${ }^{3} \mathrm{e}$ nem sempre eram muito bem aceitos pelo corpo, queria aprender a pôr 
implantes e fazer scars $^{4}$ e queria aprender mais sobre a anatomia humana. Hoje em dia, já sou formada no técnico de enfermagem, acho que me fez muito bem, ainda coloco piercings, mas finalmente aprendi a tatuar, que eu sempre quis, mas as circunstâncias nunca me foram muito favoráveis (BÁRBARA).

Há uma percepção geral de que a profissionalização é algo que vem com o tempo. Nenhum profissional se aventura a técnicas mais extremas sem ter larga experiência em tatuagens ou piercing convencionais. Pude testemunhar que os técnicos entrevistados, seja por observação nos estúdios, na casa, ou ainda pelos relatos, se mostraram interessados no trabalho e nem um pouco estagnados. Todos procuram buscar novos conhecimentos, novas técnicas, sempre participam de convenções sobre o tema e de workshops oferecidos na área.

Mas, mesmo com a profissionalização dos estúdios, a cobrança da vigilância sanitária e a popularização da profissão de tatuador e body piercer, mesmo assim os adeptos participantes da pesquisa - ainda que a grande maioria fosse branca e de classe média - eram vítimas de preconceito e associados à marginalidade. No caso das tatuagens, anunciam o caráter da pessoa que as exibem e para alguns essas marcas ainda significam uma moral negativa. Justamente o contrário do que os entusiastas tentam mostrar: coisas que consideram belas.

O mercado de trabalho é hostil às modificações. Assim, quem é simpatizante dessas práticas sente-se alvo de algumas restrições. A alternativa é optar por intervir apenas em áreas do corpo que são menos expostas. Nas modificações, há um conflito: o desejo de fazê-las e a necessidade de mantê-las escondidas no ambiente profissional. Neste campo, o sujeito deve esconder sinais que indiquem que ele não é o que se espera que ele seja (OSÓRIO, 2006).

A dificuldade de conseguir empregos em certas áreas também foi notada nas respostas das entrevistas. Nos seguintes trechos, percebe-se a preocupação dos modificados no acesso a certas profissões:

Tenho mais de 30 tatuagens e seis piercings, só tenho um surface do lado da orelha de "não convencional", e as tatuagens se concentram, em sua maioria, nas pernas, pois como fiz o técnico de enfermagem não podia ter nada nos braços e mãos e, também, pelo meio onde eu vivo, sempre pensei em ser fácil de tapar sem muito esforço, só colocar uma calça e posso voltar a ser normal de novo (BÁRBARA).

A sociedade, hoje em dia, praticamente obriga as pessoas a seguir um padrão estético e social, se você está fora dele já é alvo de julgamento tornando, assim, mais difíceis os acessos a alguns tipos de cursos e profissões, por exemplo (PANDÃO PIERCER).

A grande maioria das profissões pede discrição no visual. Um fato corriqueiro na vida do sujeito que tem tatuagens muito visíveis, independentemente de sua formação e do seu preparo para exercer deter- 
minadas atividades, é o de não conseguir emprego, salvo no próprio meio das modificações corporais ou no meio artístico. Parece, assim, que o indivíduo que se tatua não pode ser "levado a sério". A discriminação no mercado de trabalho tem mais a ver com a opinião de quem contrata do que propriamente com o ambiente; já que a aparência não influencia no ritmo da atividade do empregado, o preconceito é basicamente pessoal. Mesmo tendo um ótimo currículo é improvável que uma pessoa muito tatuada consiga vaga em uma empresa conservadora. No relato abaixo, fica evidente que Júnior não tolera o modo como são aceitas as modificações estéticas usuais enquanto as tatuagens dele são recriminadas:

O corpo já está em constante mudança, seja num corte de unha, fazer a barba, cortar cabelos. Nos tempos de hoje, cirurgias plásticas como botox, silicone nos seios são formas de interferir no corpo e causar mudança, isso é uma modificação! Por que uma siliconada pode ser uma gerente de um banco e eu com os olhos pretos ${ }^{5}$ e tatuado não?! (JUNIOR PIERCER).

Definitivamente, diz Rossi (2011), as marcas corporais expressam clara exclusão social. A sociedade exerce pressão de diversas formas para que as pessoas mantenham seus corpos dentro de um padrão. Como afirma Hertz (1980), há um controle do corpo: o corpo é sagrado, portanto se deve mantê-lo limpo, sem interferência externa ou modificações para não torná-lo profano.

Mas, independentemente dos preconceitos, o número de adeptos da tatuagem é crescente e as motivações para se tatuar variam. Para os adeptos de modificações mais corriqueiras, a que mais aparece, sem dúvida, é a estética, mas, normalmente, as marcas representam a construção de um indivíduo e estampam seus ideais. Tanto no campo social como no artístico, a emergência simbólica do corpo em geral e da pele em particular se produz tendo em conta o conjunto de signos corporais individuais, pois os símbolos exibidos através do corpo se estruturam a partir de princípios inerentes a cada indivíduo (ROSSI, 2011).

Para algumas pessoas, as tatuagens são feitas com o intuito de marcar alguma fase da vida, algo que foi importante para elas ou até de homenagear alguém ${ }^{6}$. Seguem os relatos:

Tenho umas 17 tatuagens e dois piercings no momento, apesar de já ter colocado e tirado vários. Minhas tatuagens marcam momentos da minha vida, então na sua grande maioria, elas têm um significado. Tenho uma pata de cão tatuada nas costas e ela é a mais importante. Fiz pra minha cadela que viveu 16 anos comigo e sinto falta dela todos os dias [...]. A dor faz parte, mas no final o resultado vale a pena. [...] Marcam momentos que passaram, que algumas foram sobre momentos bons como a patinha, foram tantos momentos bons que me causam falta e não voltam mais... a dor de tatuagem é válida para homenagear algo que te foi e é importante... (CAMILA). 
Tudo é uma passagem... na Nova Zelândia, eles fazem assim, eles ganham uma tattoo por merecimento, quando o guerreiro traz a cabeça do inimigo pro pajé da tribo, ele ganha uma tatuagem na cara... só assim ele ganha. É igual a essa que eu tenho aqui (mostra a tattoo do pescoço que segue até o queixo), mas eu não matei ninguém! Representa as minhas conquistas. É uma passagem... Toda tattoo tem uma história, eu olho pra cada tattoo minha e tem uma história, representam cada fase da minha vida. Uma é uma fase, outra é outra fase (ITAMAR).

Assim, o registro que fica no corpo passa a funcionar como signo que faz a pessoa lembrar algum momento vivido. A marca se torna um divisor, separando fatos que ocorreram antes e depois da modificação.

Em uma visita a um dos estúdios, conheci uma jovem que foi terminar sua tatuagem ao longo da cintura. Ela já tinha o desenho feito, faltava apenas colorir. Eram duas fadas Sininho, do filme Peter Pan, da Disney, e borboletas. Ela me contou que fez para cobrir as estrias que ficaram após o nascimento do filho. Esse tipo de tatuagem, para dissimular estrias ou cicatrizes, é bastante comum; um bom exemplo são as mulheres que fizeram a reconstrução do seio, após o câncer de mama, e tatuaram o mamilo. São tatuagens estéticas e, apesar da proximidade, é uma forma de não recorrer às cirurgias plásticas. As marcas da body modification acabam sendo úteis também para esconder outras marcas que as pessoas não querem mais expor.

Nesse dia, a mesma moça fez uma tatuagem na parte interna do lábio inferior da boca. Em honraria ao marido dela, escreveu uma frase: “Bira, te amo!". Muitas tatuagens são feitas como uma forma de homenagear pessoas queridas, gravando na pele algo que as lembrem. Uma vez inscritas na pele, elas proclamam a importância de tais pessoas na sua vida. Mostrou-me também o pulso, onde tinha gravado o nome do filho, e uma borboleta grande no antebraço. Um problema surge quando as pessoas ou coisas deixam de ser importantes e a imagem torna-se motivo de arrependimento. A jovem explicou-me que o inseto foi feito para cobrir o nome do ex-namorado. Na maioria dos casos de desgosto, tatuagens ou escarificações maiores são sobrepostas às existentes de forma a disfarçar, pois as sessões de remoção com raio laser são muito caras, além de não remover toda a imagem. Presenciei outra prova de situação semelhante quando fui observar o procedimento na casa da tatuadora Camila. Fomos buscar Jéssica (21 anos, cliente de Camila) e, no caminho, a profissional perguntou à moça o que ela desejava tatuar. Como resposta, ouviu que queria encobrir uma frase no braço dedicada à ex-namorada e que gostaria de algo parecido com o que tinha no outro braço (uma tatuagem tribal no estilo maori).

Em outra ida ao estúdio, acompanhei a visita de uma jovem que não tinha nenhuma modificação. Escolheu, na pasta com sugestões de imagens, um desenho com três borboletas e decidiu fazê-las no final das costas. Era a primeira tatuagem dela e parecia bem nervosa. Quando o tatuador 
Tiago ligou a máquina, ela logo perguntou: “Dói muito?”. Ele respondeu que era só um pouquinho. Durante todo o procedimento, ela gritava de dor. Ao final da sessão, chegou à sala da recepção, olhou pra mim e sua amiga que a acompanhava e disse: "Eu nunca mais faço uma tatuagem, gurias, eu me senti muito mal ali!". Apesar disso, ela parecia altiva, numa indescritível sensação de vitória e felicidade. Ela me mostrava as borboletas com orgulho e perguntava: "Ficou bonita a tatuagem, né?".

Durante as observações e entrevistas, foi o único caso em que alguém manifestou não querer mais se tatuar, porém, cabe comunicar que as entrevistas foram feitas com quem já possuía mais de uma tatuagem. Pelo que eu pude perceber conversando com as pessoas, elas tendem a conviver bem com suas tatuagens e sentir orgulho delas.

Atribui-se às modificações o poder de complementar o indivíduo que, após sua aquisição, se sente mais seguro e preparado para enfrentar qualquer situação, como uma forma não verbal. Em várias sociedades, o sofrimento e a dor assumem um valor ritual e, por isso, em diversos rituais de iniciação, a dor e o prazer se complementam. Nas entrevistas, isso fica claro:

Eu gosto do meu corpo, gosto de mudar ele porque eu acho divertido e a dor é irrelevante, se tu tá lá fazendo a tatuagem tu não pensa na dor, tu quer ver o resultado, gosto das minhas marcas, acho que vale a pena (SPYKE).

Sempre que decido fazer alguma intervenção no meu corpo bate, sim, aquele certo medo ou frio na barriga, mas logo paro e lembro das dores das outras modificações ou até das dores de acidentes que já passei e isso me anima, pois se já passei por tantas outras e me saí bem sem choramingar, por que não faria alguma nova com medo da dor? Cada modificação é uma experiência diferente, autoconhecimento e superação; acho que essas duas palavras resumem muita coisa (PANDÃO PIERCER).

Dessa forma, nota-se que a transição da dor ao prazer é muito sutil, a linha limítrofe é quase imperceptível, a resistência à dor proporciona maior poder e força espiritual ao indivíduo (ROSSI, 2011). Biehn (2009) diz que a dor e a tensão parecem ser o corolário das transformações que o novo corpo socializado merece. Como diz o velho ditado, não "é necessário sofrer para ficar belo"? As entrevistas com as tatuadoras evidenciam essa posição:

A maioria das pessoas diz que tem que doer mesmo, que quem não quer sentir dor é porque não merece ter tatuagem, acho que sou a favor dessa opinião, até porque tudo na vida a gente sofre pra depois ver o lado bom, se fosse fácil não teria graça afinal de contas (BÁRBARA).

A grande maioria chega com medo, não sabe se vai aguentar, geralmente pergunta sobre anestésicos ou coisas para relaxar. Pelo jeito, a dor não é tão bem vista pra maioria. Eu já acho que faz parte e modificações sem dor, não são para pessoas dignas disso (CAMILA). 
Grande parte definiu a dor das modificações como suportável e compreendida como parte do procedimento. É notável, na fala dos técnicos, a importância de passar por essa prova, ou seja, aguentar o sofrimento é um ato de coragem e só quem enfrenta isso é "digno" de ser modificado. De fato, durante muito tempo a tatuagem serviu para afirmar a virilidade (LE BRETON, 2002, 2010). Atualmente, em nossa sociedade, os indivíduos temem a dor e a combatem com todo tipo de analgésicos. A tatuagem, não obstante, segue sendo dolorosa, já que sua realização exige tempo e invade a carne, mas para a maioria dos tatuados a dor é sublimada pelo processo paralelo que a acompanha, pela metamorfose que anuncia, pela satisfação de realizar um feito desejado. Assim, a dor que provoca a inscrição de uma marca sobre a pele costuma associar-se com a sensação de estar vivo, de sentir-se vivo (LE BRETON, 2013).

As marcas no corpo estabelecem uma conexão indissolúvel com ele, transferindo essas sensações dolorosas para o mundo real e tangível. A dor é algo individual e exterioriza a verdadeira personalidade do sujeito e reconstrói a identidade integral do "eu" (ROSSI, 2011). A dor serve, então, também para demarcar quem é pertencente ao grupo.

Fica claro nos discursos o contentamento e a satisfação em ter domínio sobre o corpo. As pessoas podem construí-lo conforme seu desejo para tentar fugir de uma sociedade na qual é difícil a sobrevivência de características individuais. Assim como o mundo, onde tudo muda rapidamente, as técnicas utilizadas pela body modification criam novas formas e fazem com que o corpo torne-se diverso e surpreendente.

Há uma construção de identidade por meio da "fabricação" do corpo; o indivíduo modificado forma sua personalidade através de suas próprias marcas. A pele como superfície simbólica gera um intercâmbio social, certamente ela representa um elemento substancial de conexão e, desde aí, se impõe também como elemento cultural e simbólico. A identidade, então, depende do olhar do outro, e essa noção é construída em relação a algo que é externo. Numa sociedade como a brasileira, e em termos de sociedades ocidentais, onde o culto ao corpo é predominante, a valorização da aparência inscreve-se num processo em que o corpo físico assume um papel fundamental na exteriorização da subjetividade e na construção das identidades (IRIART et al., 2009).

As modificações corporais voluntárias estiveram presentes em praticamente toda a história humana, do neolítico aos tempos modernos. Dessa forma, homens e mulheres exploram seus corpos desenvolvendo técnicas a fim de conhecê-los e embelezá-los, como opções oferecidas por nossa sociedade como reencontro corporal.

Não é estranho que, desde tempos imemoriáveis, o ser humano tenha escrito sua história na pele. O corpo sempre esteve em foco nas sociedades e talvez a própria história da humanidade se confunda com a das práticas das modificações. Sabe-se da existência de evidências de marcações corporais nas sociedades mais "primitivas". A mais antiga foi 
uma tatuagem encontrada no "homem de gelo" que remonta ao ano 2500 a.C.

Segundo Dossin e Ramos (2008), a tatuagem parece ser a antecessora, uma espécie de "abre-alas" para essa cultura denominada body modification. Como já dito, esse conceito é usado para designar as modificações corporais das mais diversas formas - irreversíveis ou não - e feitas por uma razão que não seja saúde, e nos apresenta uma nova realidade na qual o corpo - que em quase todas as sociedades é palco de interferências culturais - passa por dolorosas transformações (PIRES, 2005).

Assim, grupos de pessoas de países ocidentais vêm se inspirando em técnicas corporais utilizadas por sociedades não ocidentais para criarem as suas próprias práticas. Mas, segundo David Le Breton (2013), mesmo que os desenhos possam coincidir, os significados sociais da tatuagem diferem radicalmente entre as sociedades tradicionais e as nossas. Nas primeiras, a tatuagem nunca é um fim em si mesmo, é sempre acompanhada de cerimônias ou de ritos de passagem.

Sara Silva (2009) afirma que, no processo de marcar os indivíduos nos rituais das sociedades tribais, o sujeito é posto em um lugar de entrega, de vulnerabilidade, enquanto outros manipulam seu corpo. Porém, por trás dessa submissão, o corpo evoca um caráter de resistência. As práticas rituais tradicionais são conduzidas por agentes especializados (xamãs ou pajés), ou seja: mediadores entre o mundo real e o espiritual. As marcas modernas, apesar de voluntárias, têm a mesma característica de superação dos limites corporais e a posse de maior poder sobre seu corpo, mas enquanto nas sociedades tradicionais o momento corporal é de uma ritualidade mais ampla, a pessoa não pode se singularizar, ou seja: a pessoa é membro de um grande corpo comum, já nas nossas sociedades, cada um pretende ser um corpo específico.

Nas comunidades tradicionais, o passado é venerado e os símbolos são valorizados porque contêm e perpetuam a experiência de gerações. A tradição é um meio de lidar com o tempo e o espaço, inserindo qualquer atividade ou experiência particular na continuidade do passado, presente e futuro, os quais, por sua vez, são estruturados por práticas sociais recorrentes (GIDDENS, 1990 apud HALL, 2006). Já as sociedades modernas são, por definição, sociedades de mudança constante, rápida e permanente. O sujeito pós-moderno é conceituado por Stuart Hall (2006) como quem não tem uma identidade fixa e essencial. A identidade torna-se uma "celebração móvel" formada e transformada continuamente em relação às formas pelas quais somos representados ou interpelados nos sistemas culturais que nos rodeiam. Assim, a identidade plenamente unificada, completa, segura e coerente é uma fantasia. Ao contrário, na medida em que os sistemas de significação e representação cultural se multiplicam, somos confrontados por uma multiplicidade desconcertante e cambiante de identidades possíveis, com cada uma das quais poderíamos nos identificar - ao menos temporariamente. 
Diferentemente das sociedades contemporâneas, que têm ênfase no individualismo, nas sociedades tradicionais o status de uma pessoa era subordinado completamente ao coletivo. O corpo era integrado por uma obrigação social de práticas simbólicas cotidianas. O corpo da modernidade é o resultado do individualismo ocidental que traduz o fechamento do sujeito em si mesmo. É o elemento que marca os limites da pessoa, onde começa e acaba a presença do indivíduo. Ele é entendido, primeiramente, como o modo de vida de cada sujeito.

Nas sociedades urbanas atuais estudadas, as tatuagens se individualizam, marcam a um sujeito singular cujo corpo não serve de nexo nem com a comunidade, nem com o cosmo, como acontece nas sociedades tradicionais, mas, pelo contrário, certifica sua indissolúvel individualidade. A tatuagem atual responde a uma decisão pessoal que em nada afeta o status social; a escolha do desenho é uma iniciativa particular, uma elaboração íntima e uma preferência estética, não um gesto de adesão ou um gesto cultural socialmente compartilhado. Dessa forma, isso o obriga a ter que explicar aos demais o significado subjetivo da sua tatuagem. Separada dos sistemas culturais, a tatuagem hoje é uma iniciativa pessoal que se completa com um relato que a confere um significado importante, mas íntimo, uma poderosa redefinição do "eu”.

De acordo com David Le Breton (2003), hoje a relação do indivíduo com seu corpo ocorre sob o respaldo do próprio domínio. O homem e a mulher contemporâneos são convidados a construir o corpo, modelar sua aparência. Assim, uma das diferenças entre as sociedades tradicionais e as urbanas é que, nessas últimas, a decisão de se tatuar é eminentemente pessoal, enquanto nas primeiras, a participação é decorrente da tradição, socialização e educação corporal do coletivo social.

$\mathrm{O}$ avanço da ciência, juntamente com a diversidade, possibilita ao indivíduo alterar seu corpo. O domínio do sujeito sobre ele mesmo tem seu paradigma na relação com o próprio corpo. O esvaziamento de sentido dos sistemas sociais traz consigo uma maior centralidade do eu; é como se apenas restasse acreditar e confiar no próprio corpo (LE BRETON, 2013). Assim, a interioridade do sujeito é um esforço constante de exterioridade, é necessário ver-se desde fora para afirmar sua identidade (LE BRETON, 2003).

Conforme o observado, para os tatuados contemporâneos, as marcas físicas são o que confere a eles uma identidade e os difere dos demais. Dessa forma, sem suas tatuagens, deixariam de ser eles mesmos. A tatuagem objeto, ao mesmo tempo privado e público, existe para ser vista e apreciada pelos outros, mesmo que seja com uma simbologia íntima. Ela encarna uma maneira de se mostrar construindo simbolicamente o próprio personagem, aumentar a autoconfiança e uma sensação de domínio sobre si mesmo (LE BRETON, 2013).

Tatuagens provocam olhares, afirmam um look e chamam a atenção; são uma forma de comunicação, de revalorização do próprio sujeito 
para esquivar a indiferença. $\mathrm{O}$ tatuado grifa o que ele pretende ser e busca, através da sua aparência, evidenciar um discurso sobre si mesmo. A tatuagem, então, se converte numa assinatura do "eu".

A vontade de se tatuar é incentivada pelo apelo social através dos meios de comunicação. Já apropriada pelo sistema da moda, da publicidade e da mídia, a tatuagem (quando não muito volumosa, em grande número, ou em local muito vistoso) transforma-se em adorno comum e aceito pela sociedade. Pessoas famosas ostentam tatuagens e se transformam em outdoors da prática. $\mathrm{O}$ uso da mídia e da internet permite a divulgação e o fácil acesso à obra dos artistas e estas, associadas à moda, buscam denunciar os preconceitos (PIRES, 2005). Assim, o sucesso das marcas corporais vem aumentando em associação com a ideia de que o corpo é maleável e remanejável. Essas modificações, no contexto pesquisado, saem da marginalidade e são absorvidas pelas tribos urbanas e se propagam na sociedade. A demanda de estúdios de tatuagem e piercing, por exemplo, aumenta a cada dia (LE BRETON, 2003).

Essa expressão do eu através da pele provoca a captação dos olhares dos outros, o que era subjetivo, espaço privado, torna-se uma espetacularização. A identidade, então, depende do olhar alheio, e essa noção é construída em relação a algo que é externo. Numa sociedade como a brasileira, e em termos de sociedades ocidentais, onde o culto ao corpo é predominante, a valorização da aparência inscreve-se num processo em que o corpo físico assume um papel fundamental na exteriorização da subjetividade e na construção das identidades (IRIART et. al., 2009). Como afirma David Le Breton (2013), em uma sociedade de aparências, da imagem, do espetáculo, é necessário se converter em imagem para ter a sensação de existir plenamente no olhar do outro.

Assim, o corpo se torna em mediador simbólico entre os indivíduos. Como na nossa sociedade o sentido mais desenvolvido é o da visão, a imagem é o modo que o indivíduo percebe o outro, e a construção do corpo, conforme o desejo de seu dono, surge como opção dessa "sociedade visual" (PIRES, 2005). A forma de expressão primeira entre os que se modificam não passa pela palavra, se dá, espontaneamente, pela diferença estética causada pelas intervenções corporais que cada um possui.

\section{CONSIDERAÇÕES FINAIS}

Tive como objetivo aqui evidenciar o discurso dos meus interlocutores tatuados e analisar a tatuagem a partir da visão das Ciências Sociais. Durante a pesquisa, constatou-se que as marcas corporais acompanham o corpo de homens e mulheres, desde os primórdios, conforme o círculo social em que ele está inserido. Através dessas marcações é possível reconhecer particularidades de culturas e também traços subjetivos individuais.

Todas as sociedades humanas abrigam o desejo de converter a presença no mundo e no corpo em uma obra que seja própria. Nunca o 
homem e a mulher existiram em estado selvagem, sempre estão imersos em uma cultura, ou seja, em um universo de significados e valores (LE BRETON, 2013).

As modificações marcam a dominação do sujeito sobre seu corpo que, graças ao progresso da ciência, torna-se flexível e submetido à vontade do indivíduo. Devido a esses avanços tecnológicos, ele passa a representar uma mistura do "natural" e do adquirido. O sujeito seria o criador e, pensando dessa forma, tudo o que ele produz é compartilhado com sua comunidade. Neste contexto social, mulheres e homens concebem e partilham seus valores e representações entre si.

No meu dia a dia no campo, pude perceber que mulheres jovens são as que mais buscam por tatuagem. Os profissionais que fazem os procedimentos me confirmaram que elas procuram, de fato, interferir no corpo de forma mais frequente que os rapazes.

Interpretando as entrevistas que fiz, encontrei vários motivos que levaram os sujeitos a se tatuar, entre eles a vontade de homenagear alguém, a espiritualidade, a estética, o erotismo, entre outros, mas os principais são: a vontade de se diferenciar, deixar o corpo mais bonito e construir uma identidade. Para a pergunta "Qual o significado de seu corpo para você?" os retornos dados, majoritariamente, foram: "uma tela", "um álbum de figurinhas" e "meu cartão de visitas". As respostas eram bastante subjetivas sobre o que desejavam simbolizar. O contexto, ambiente, época, nível cultural, influência, modismo, ideologia, crença e espírito despojado são algumas das justificativas que podem dar vazão ao processo. Não há uma forma definida que explique o desejo e sua efetivação na realização das modificações, um evento a princípio antinatural, biologicamente falando. Creio eu que o dono do corpo, independentemente de sua motivação, é quem sabe o que deve fazer com ele. O indivíduo adulto é o patrão do seu próprio corpo, portanto, só ele decide.

\section{NOTAS}

1. Vários piercings ligados por uma fita mimosa, como se fosse um espartilho.

2. Esse conceito é usado para designar as modificações corporais das mais diversas formas (irreversíveis ou não).

3. Surface é um piercing mais comprido, com as pontas curvas, feito nas superfícies da pele. Diferente de outras perfurações, que precisam atravessar o tecido de um lado ao outro, os furos de entrada e saída do surface ficam na mesma altura da pele. Funciona como uma espécie de implante subcutâneo.

4. Escarificações.

5. Refere-se ao eyeball tattoo - tatuagem no glóbulo ocular.

6. Esse foi o único motivo de "arrependimento" de ter feito uma tatuagem, citado por alguns entrevistados. 


\section{REFERÊNCIAS}

ABREU, Nathalia; SOARES, Priscila. Corpo ao extremo: a nova face de uma cultura modificada. Jundiaí: Editora In House, 2012.

ARAÚJO, Leusa. Tatuagem, piercing e outras mensagens do corpo. São Paulo: Cosac Naify, 2005.

BIEHN, Michel. Cruel coquetería. Trad. Francisco López Martín. Barcelona: Océano, 2009.

BRAZ, Camilo Albuquerque. Além da pele: um olhar antropológico sobre a body modification em São Paulo. Campinas: [s. ed.], 2006.

DOSSIN, Francielly Rocha Dossin; RAMOS, Célia Maria Antonacci. Corporalidades no urbano contemporâneo: a body modification e os modern primitives. In: IV ENECULT - Encontro de Estudos Multidisciplinares em Cultura, Faculdade de Comunicação, UFBa, Salvador, Bahia, 2008.

DOUGLAS, Mary. Los dos Cuerpos. In: DOUGLAS, Mary. Símbolos naturales: exploraciones en cosmologia. Madrid: Alianza, 1978.

DOUGLAS, Mary. As abominações do Levítico. In: DOUGLAS, Mary. Pureza e perigo: ensaio sobre as noções de poluição e tabu. Lisboa: Edições 70, 1991.

HALL, Stuart. Identidade cultural na pós-modernidade. Rio de Janeiro: DP\&A, 2006.

HERTZ, R. A preeminência da mão direita: um estudo sobre a polaridade religiosa. Religião e Sociedade, n. 6, p. 99-128, 1980.

IRIART, Jorge Alberto Bernstein; CHAVES, José Carlos; ORLEANS, Roberto Ghignone de. Culto ao corpo e uso de anabolizantes entre praticantes de musculação. Cadernos de Saúde Pública, v. 25, n. 4, p. 773-782, 2009.

JEHA, Silvana. Uma história da tatuagem no Brasil. São Paulo: Veneta, 2019.

LEBRETON,David.Signesd'identité:tatouages, piercingsetautresmarques corporelles. Paris: Métailié, 2002.

LE BRETON, David. Adeus ao corpo: antropologia e sociedade. Campinas: Papirus, 2003.

LE BRETON, David. Escarificações na adolescência: uma abordagem antropológica. Horizontes Antropológicos, Porto Alegre, v. 16, n. 33, p. 25-40, jan./jun. 2010.

LE BRETON, David. La sociología del cuerpo. Buenos Aires: Nueva Visión, 2011.

LE BRETON, David. El tatuaje o la firma del yo. Casimiro libros: Madrid, 2013.

OSÓRIO, Andrea. O gênero da tatuagem: continuidades e novos usos relativos à prática na cidade do Rio de Janeiro. Rio de Janeiro: UFRJ, 2006.

PIRES, Beatriz Ferreira. O corpo como suporte da arte: piercing, implante, escarificação, tatuagem. São Paulo: SENAC, 2005.

ROSSI, Sandra Martínez. La piel como superfície simbólica: procesos de transculturación en el arte contemporáneo. Madrid: FCE, 2011. 
SILVA, Sara Panamby Rosa da.Corpo Limite: uma análise dos corpos modificados. 2009. 64f. Monografia (Bacharelado em Performance) Curso de Comunicação das Artes do Corpo, PUC-SP, São Paulo, 2009. VELHO, Gilberto. Observando o Familiar. In: NUNES, Edson de Oliveira (org.). A aventura sociológica: objetividade, paixão, improviso e método na pesquisa social. Rio de Janeiro: Zahar, 1978.

SUBMETIDO EM: 08/05/2020

APROVADO EM: 25/09/2020 